\title{
Nanoindentation Measurements of Mechanical Properties of Polyurethane Elastomers Which Crosslinked by $\beta$-Cyclodextrin
}

\author{
An Xie', Xiaoyuan Ji², Yingjie Chen1, Ming Zhang'2, Shin-Ichi Inoue1 \\ ${ }^{1}$ Department of Applied Chemistry, Aichi Institute of Technology, Toyota, Japan \\ ${ }^{2}$ Schoolof Chemistry and Chemical Engineering, Yangzhou University, Yangzhou, China \\ Email:w13871ww@aitech.ac.jp
}

Received 30 June 2016; accepted 25 July 2016; published 28 July 2016

Copyright (C) 2016 by authors and Scientific Research Publishing Inc.

This work is licensed under the Creative Commons Attribution International License (CC BY). http://creativecommons.org/licenses/by/4.0/

\section{c) (i) Open Access}

\begin{abstract}
A series of PUEs which use $\beta$-CD as cross-linker were synthesized. Nanoindentation measurements of mechanical properties of these PUEs were made. Load and depth sensing indentation and nano DMA mode were used to evaluate mechanical properties of PUEs in nano-scale. The difference between the results from two modes proved the microphase separation in PUEs and to investigate PUE from hard domains and soft domains was of great significance.
\end{abstract}

\section{Keywords}

Polyurethane Elastomer, Microphase Separation, Load and Depth Sensing Indentation, Nano DMA

\section{Introduction}

PUEs are a kind of polymers that typically synthesized by polyaddition of diisocyanate, polyol and chain-extender (CE)/cross-linker. PUEs are widely believed as segmented polymers which contain hard segments (HS) and soft segments (SS). Isocyanate and chain-extender components give rigidty to molecular chains and called HS, while polyol gives flexibility to chains and they are called SS [1] [2]. Due to the incompatibility between HS and SS, most PUEs exhibit phase separation which plays an important role in affecting PUE properties [3]. The phase separation phenomenon has been widely researched and proved by images of Atomic Force Microscope (AFM) [4] [5] that hard domains (HD) consist of agglomerate of hard segments, soft domains (SD), and 
soft segments. Mechanical properties of PUEs and the structure-properties relationship have been investigated by lots of researchers [6]-[8]. However, the mechanical properties characterized from HS/HD and SS/SD themselves attract fewer researchers' attention. It is believed that the mechanical properties of small structure are quite different from bulk materials [9] [10].

In recent years, nanoindentation measurement has become a popular method of determining mechanical properties of materials, especially thin film systems [11]. For PUEs, the nano-scaled size of indenter makes it possible to characterize mechanical properties of HD and SD directly.

In this study, normal load and depth sensing indentation and nanoscale Dynamic Mechanical Analysis were carried out. Nano-scale mechanical properties were characterized from PUEs, also from HD and SD. The results show that properties of PUEs are quite related to phase separation and the characterization from HD and SD is of great significance.

\section{Experimental}

\subsection{Materials}

Three kinds of diisocyanates (4,4'-Diphenylmethane diisocyanate (MDI), hexamethylene diisocyanate (HDI), and isophorone diisocyanate (IPDI)) were supplied by Tosoh Industry, Tokyo, Japan and were purified by distillation under reduced pressure $(267-400 \mathrm{~Pa})$ at $100^{\circ} \mathrm{C}$ before use. Polytetramethylene ether glycol (molecular weight $=1000)($ PTMG1000) was supplied by Invista Industry, Texas, USA. $\beta$-cyclodextrin $(\beta$-CD) was purchased from Nacalai Tesque, Inc., Kyoto, Japan (Nacalai) and was dried for 24 hours under a condition of 267 $400 \mathrm{~Pa} / 80^{\circ} \mathrm{C}$ before use. $N, N$-Dimethylformamide (DMF) was purchased from Nacalai and stored over $4 \AA$ molecular sieves before use. Dibutyltin dilaurate (DBTDL) was purchased from Nacalai and initially dissolved in toluene to form $10 \%$ solution. Tetrahydrofuran (THF) was purchased from Nacalai and distilled over calcium hydride under an Ar atmosphere.

\subsection{Synthesis of PUEs Crosslinked by $\beta$-Cyclodextrin}

A series of PUEs were synthesized from different kinds of diisocyanates, PTMG1000, and $\beta$-CD via prepolymer method, named X-PUEx (X = kind of diisocyanate, $\mathrm{x}=$ weight percent $(\mathrm{wt} \%)$ of $\beta$-CD).

The synthesis route is as follows: $\beta$-CD was initially dissolved in DMF $(10 \mathrm{~mL})$ at $80^{\circ} \mathrm{C}$ for 20 min under an Ar atmosphere to reach a $\beta$-CD solution. Diisocyanate $(0.020 \mathrm{~mol})$ and PTMG1000 (10 g, $0.010 \mathrm{~mol})$ were added into a $100 \mathrm{~mL}$ four-necked separable flask equipped with a mechanical stirrer, a gas inlet tube, and a reflux condenser. The prepolymer was prepared at $80^{\circ} \mathrm{C}$ under an $\mathrm{Ar}$ atmosphere with a stirring. Temperature of reaction was controlled at $80^{\circ} \mathrm{C}$ for MDI- and IPDI-based prepolymer, while $100^{\circ} \mathrm{C}$ for $\mathrm{HDI}$-based prepolymer. Then $\beta$-CD solution was added into separable flask followed by a further stirring. A small amount of bubbles in the system were removed by addition of THF $(20 \mathrm{~mL})$ and a high speed stirring of $5 \mathrm{~min}$. Catalyst (DBTDL) was also needed when HDI and IPDI were used.

The thin PUE films $(0.5-0.8 \mathrm{~mm})$ were obtained by casting the resulting PUE solution at room temperature $\left(23^{\circ} \mathrm{C} \pm 2^{\circ} \mathrm{C}\right)$ for $24 \mathrm{~h}$, at $50^{\circ} \mathrm{C}$ for $24 \mathrm{~h}$ and at $100^{\circ} \mathrm{C}$ for $24 \mathrm{~h}$. The DMF residues in films were removed at $80^{\circ} \mathrm{C}$ under vacuum for $6 \mathrm{~h}$.

\subsection{Nanoindentation Measurements of Mechanical Properties}

The nanoindentation experiments of PUE films have been performed on a TI 950 TriboIndenter ${ }^{\circledR}$ of Hysitron Inc., MN, USA, load and depth sensing indentation mode and nanoscale Dynamic Mechanical Analysis (nano DMA) were undertook. In nano DMA tests, surface images were also took during the tests, the tested areas were marked in the images. A Berkovich tip is used in all nanoindentation experiments. All measurements were performed at room temperature. In Load and depth sensing indentation mode, indentation area of specimens were selected randomly. Each sample was test for 5 to 7 times.

\subsection{Theory}

Some parameters in indentation with Berkovich tip are illustrated in Figure 1. Load-depth curves produced by instrumented indentation systems are often based on Oliver and Pharr [12]. As Figure 2 shown, several important 


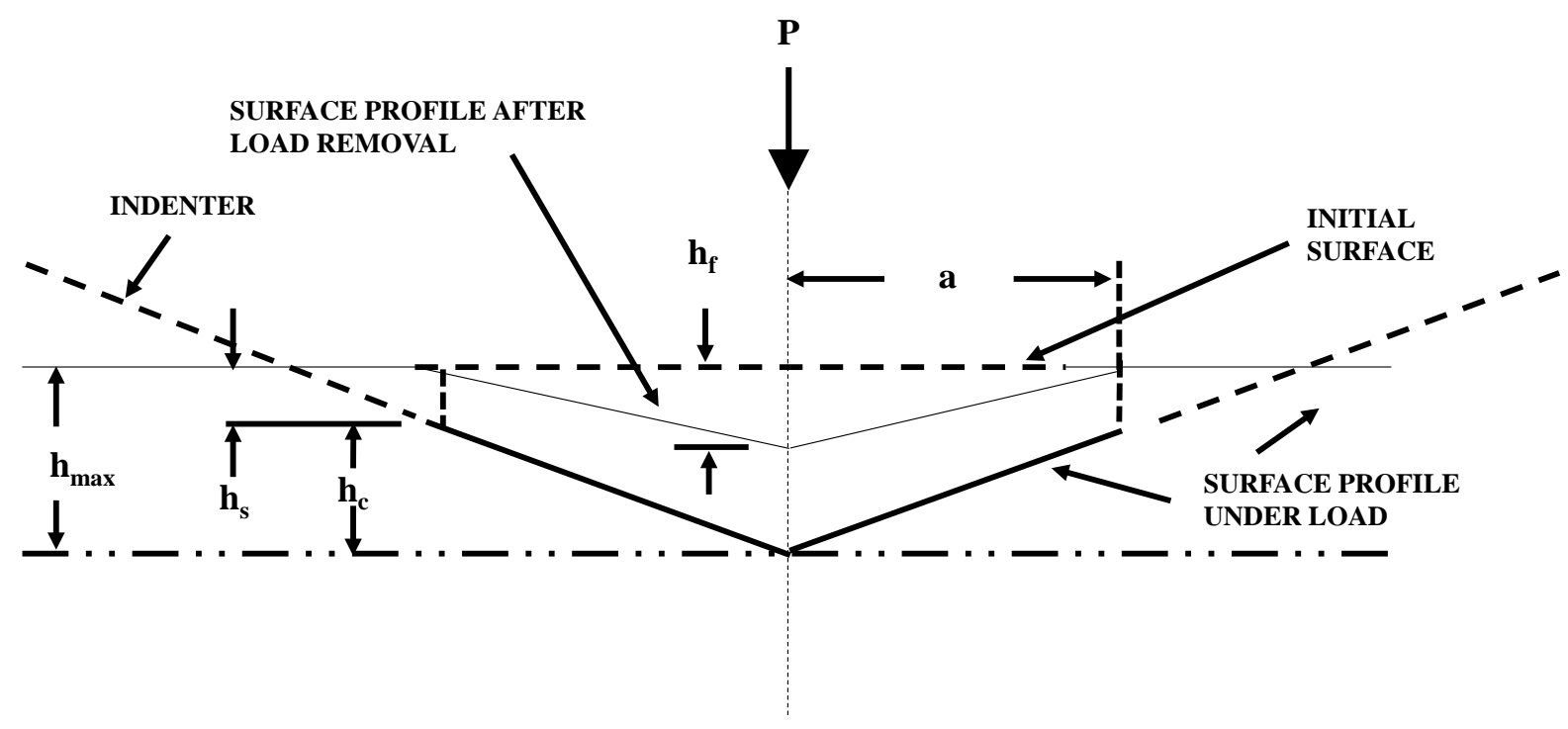

Figure 1. A schematic representationof the indentation.

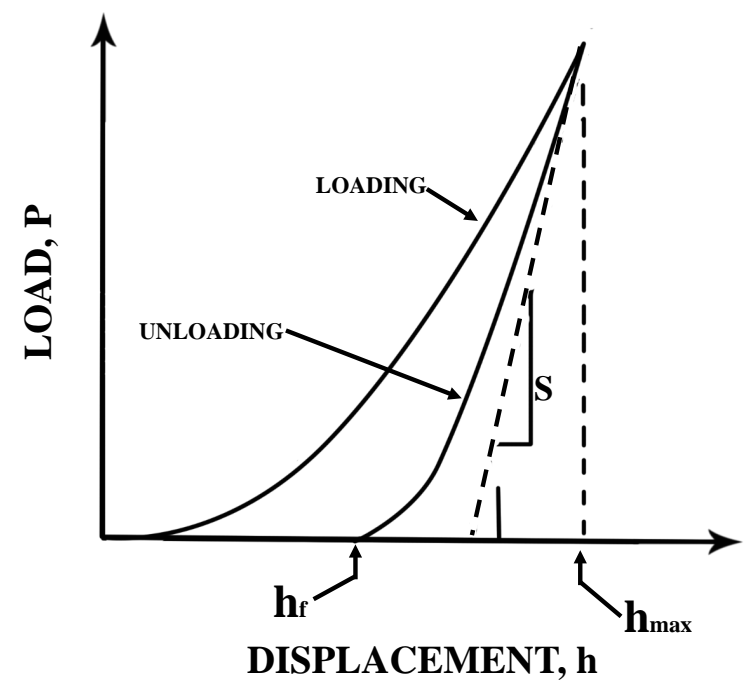

Figure 2. A schematic representationof Load-depth curve.

parameters are illustrated. The hardness $H$ is an important parameter to evaluate mechanical property of materials. $H=P_{\max } / A$, where $P_{\max }$ is the peak indentation load and $\mathrm{A}$ is projected area of the hardness impression [13] [14].

\section{Results and Discussion}

The load-depth curves of PUEs are shown as Figure 3. In MDI-PUEs and HDI-PUEs, $h_{\max }$ of MDI-PUE and HDI-PUE $_{0}$ are lower than the PUEs with $\beta$-CD. In contrast, IPDI-PUEs that contain $\beta$-CD have much lower $h_{\max }$ than IPDI-PUE $E_{0}$. The calculated hardness of these PUEs is shown as Table 1. It is concluded that addition of $\beta$-CD reduce the hardness of MDI-PUE $\mathrm{M}_{0}$ and HDI-PUE . Whereas, increase the hardness of IPDI-PUE $_{0}$. These results prove that $\beta$-CD can increase the hardness of PUEs synthesized from unsymmetrical diisocyanates and decrease the hardness of PUEs synthesized from symmetrical ones. It quite agrees with our former research.

In addition, the increase and decrease of hardness is not proportional to the additive amount of $\beta$-CD. It may relate to the tested area of indenter. Because phase separation occurs in most PUEs, the indenter may contact the HD and SD. The differences between HD and SD affect the indentation a lot. 
To ensure the differences, nano DMA mode was used. As Figures 4-6 shown, hardness of designated areas was tested. Most PUEs exhibit phase separation and brighter parts have comparatively greater hardness. Normally, brighter parts are believed to be HD while darker parts are SD. Moreover, hardness of brighter parts and darker parts reach unanimity in high depth. It may due to the unique structure of PUEs. HD are dispersed in SD matrix, thus indenter tend to contact the matrix in high depth both in SD and HD areas.

In PUEs which exhibit weak phase separation or no phase separation, such as MDI-PUE 1, MDI-PUE $_{3}$, IPDI-PUE $_{1}$ and IPDI-PUE $E_{5}$, the hardness of different areas are almost the same. It is obvious that phase separation is important to PUEs and the greater the phase separation the greater difference between hardness of HD and SD.

\section{Conclusion}

A series of PUEs which cross-linked by $\beta$-CD were synthesized. Through nanoindentation measurements of mechanical properties of these PUEs, properties of HD and SD of PUEs can be measured directly. It is more
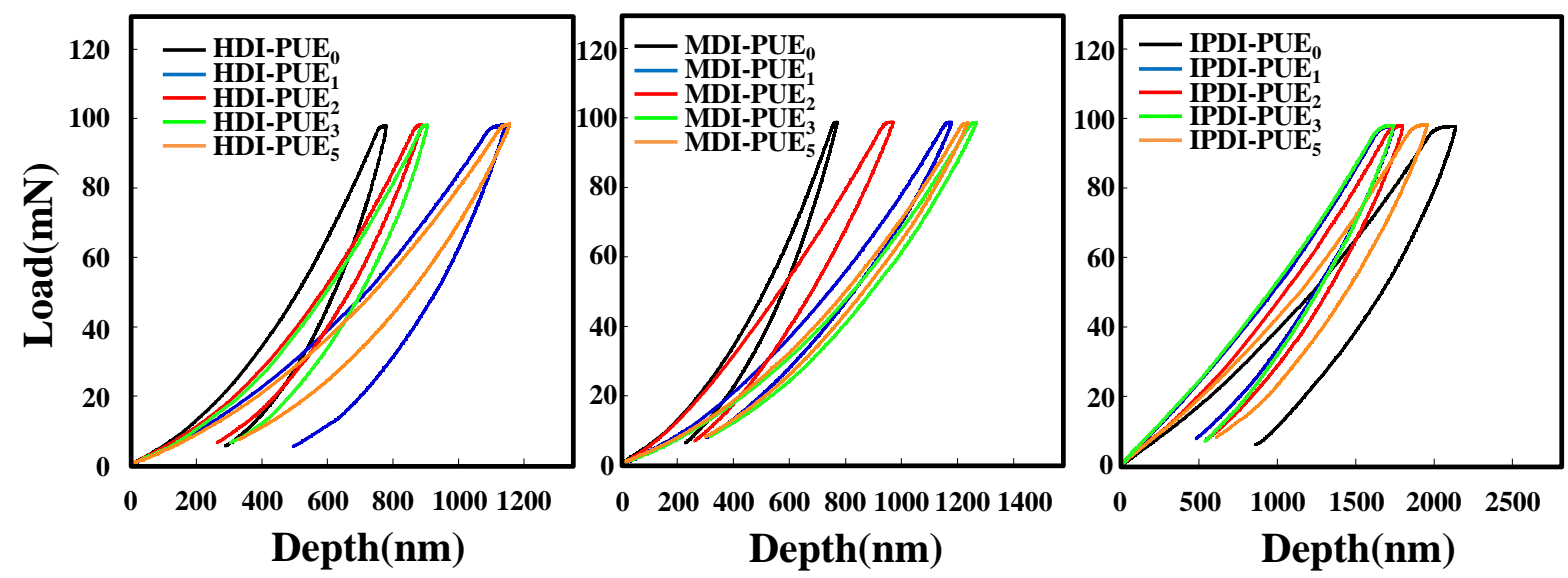

Figure 3. Load-depth curves of HDI-PUEs, MDI-PUEs and IPDI-PUEs.

Table 1. Calculated hardness of HDI-PUEs, MDI-PUEs and IPDI-PUEs.

\begin{tabular}{lll}
\hline Sample & Calculated hardness (Gpa) \\
\hline HDI-PUE $_{0}$ & 0.0138 \\
HDI-PUE $_{1}$ & 0.0050 \\
HDI-PUE $_{2}$ & 0.0087 \\
HDI-PUE $_{3}$ & 0.0072 \\
HDI-PUE $_{5}$ & 0.0064 \\
MDI-PUE $_{0}$ & 0.0135 \\
MDI-PUE $_{1}$ & 0.0078 \\
MDI-PUE $_{2}$ & 0.0113 \\
MDI-PUE $_{3}$ & 0.0061 \\
MDI-PUE $_{5}$ & 0.0067 \\
IPDI-PUE $_{0}$ & 0.0016 \\
IPDI-PUE $_{1}$ & 0.0033 \\
IPDI-PUE $_{2}$ & 0.0028 \\
IPDI-PUE $_{3}$ & 0.0032 \\
IPDI-PUE $_{5}$ & 0.0024 \\
\hline
\end{tabular}




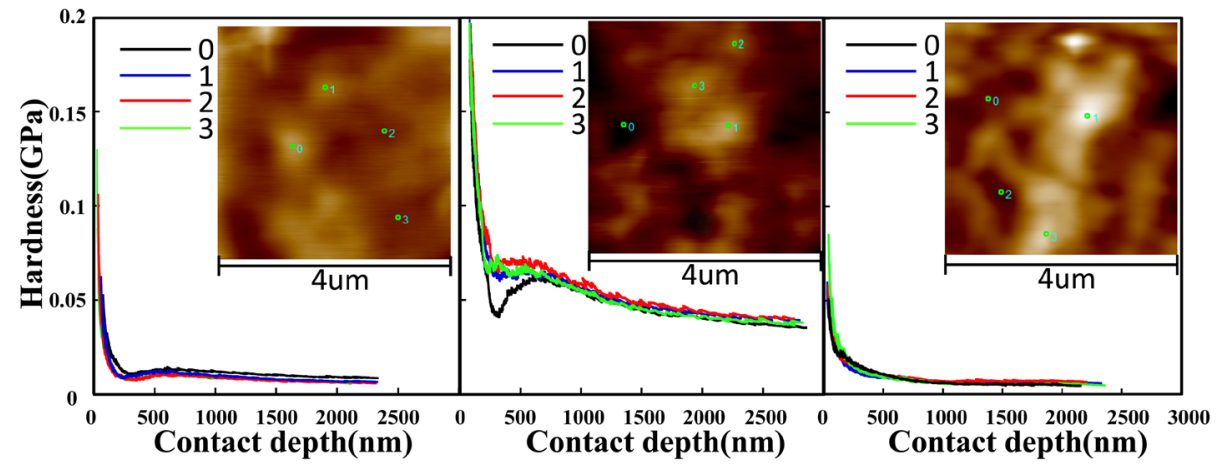

(a)

(b)

(c)

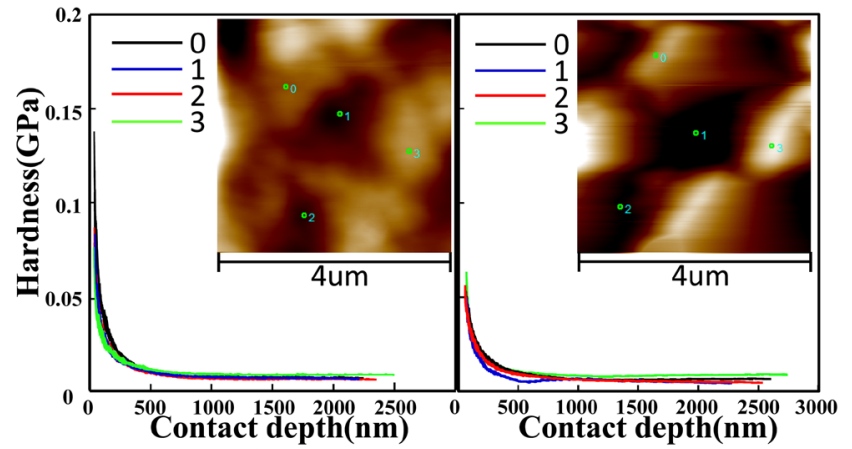

(d)

(e)

Figure 4. Hardness-depth curves of HDI-PUEs, (a) HDI-PUE . (b) HDI-PUE $_{1}$. (c) HDI-PUE . (d) HDI-PUE 3 . (e) HDI-PUE 5 .

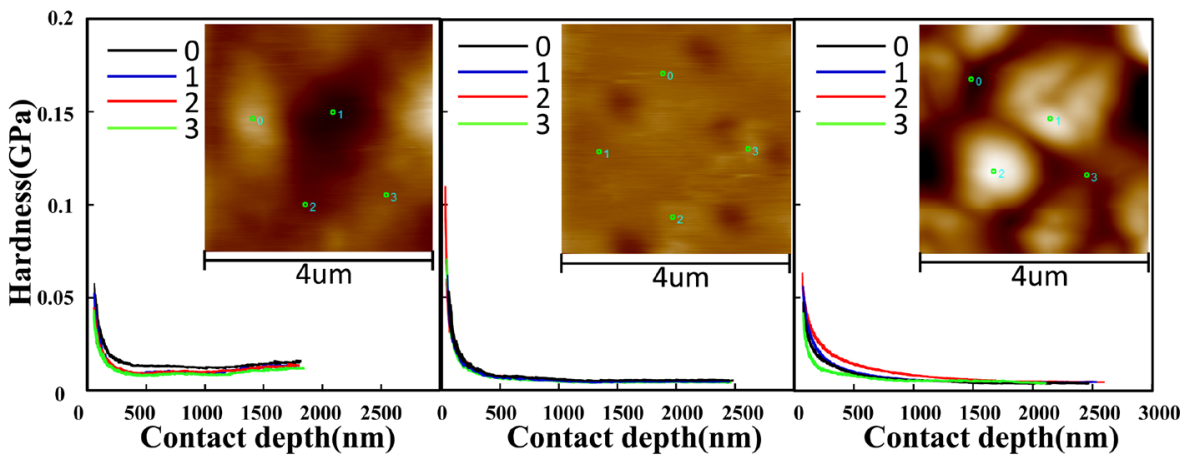

(a)

(b)

(c)

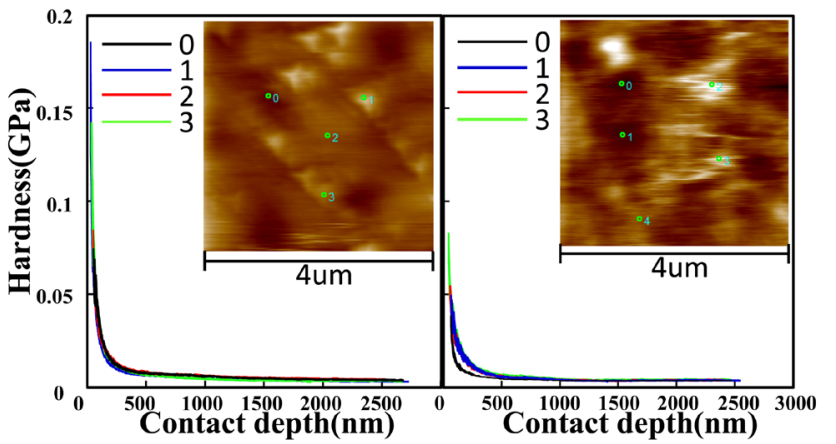

(d)

(e)

Figure 5. Hardness-depth curves of MDI-PUEs, (a) MDI-PUE . (b) MDI-PUE $_{1}$. (c) MDI-PUE . (d) MDI-PUE . $_{3}$ (e) MDI-PUE 5 . 


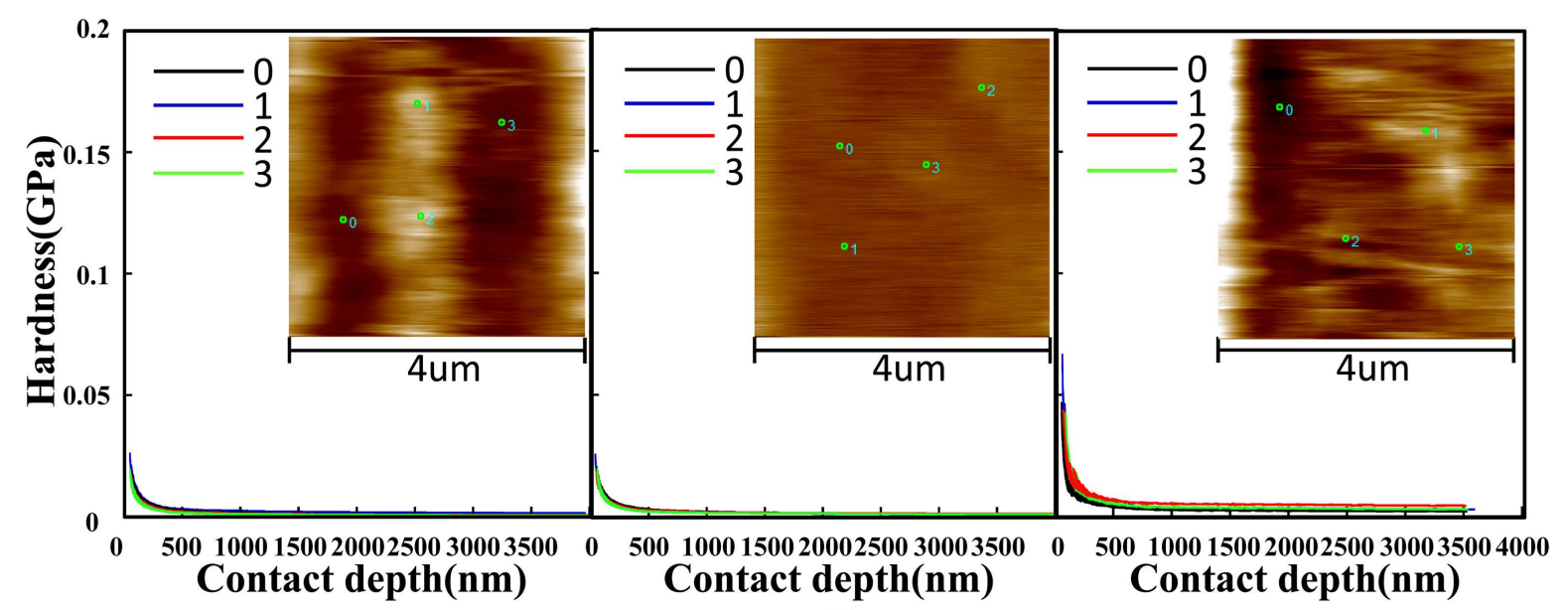

(a)

(b)

(c)

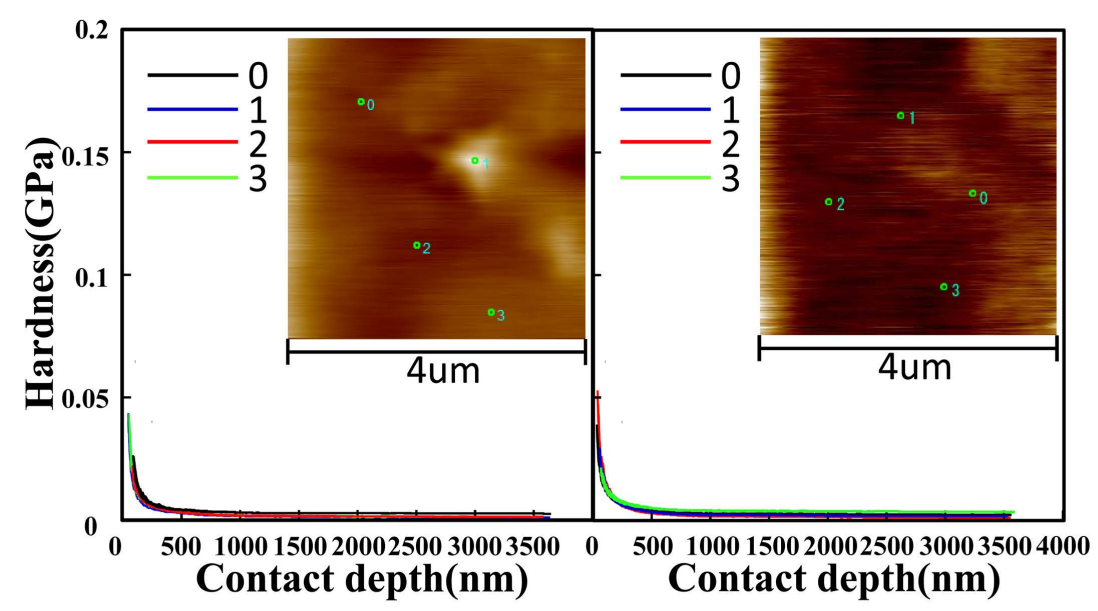

(d)

(e)

Figure 6. Hardness-depth curves of IPDI-PUEs, (a) IPDI-PUE . $_{\text {. (b) IPDI-PUE }}$. (c) IPDI-PUE IP $^{\text {(d) IPDI-PUE }}$. (e) IPDI$\mathrm{PUE}_{5}$.

accurately and directly to measure mechanical properties of PUEs on HD and SD of PUEs, to compare with direct characterization on PUEs.

\section{References}

[1] Szycher, M. (1999) Szycher’s Handbook of Polyurethanes. CRC Press, Boca Raton, Florida.

[2] Randall, D. and Lee, S. (2003) The Polyurethanes Book.

[3] Prisacariu, C. (2011) Polyurethane Elastomers. From Morphology to Mechanical Aspects. Springer, Vienna. http://dx.doi.org/10.1007/978-3-7091-0514-6

[4] Korley, L.T.J., Pate, B.D., Thomas, E.L. and Hammond, P.T. (2006) Effect of the Degree of Soft and Hard Segment Ordering on the Morphologyand Mechanical Behavior of Semicrystalline Segmented Polyurethanes. Polymer, 47, 3073-3082. http://dx.doi.org/10.1016/j.polymer.2006.02.093

[5] Abouzahr, S., Wilkes, G.L. and Ophir, Z. (1982) Structure-Property Behaviour of Segmented Polyether-MDI-Butane diol Based Urethanes: Effect of Composition Ratio. Polymer, 23, 1077-1086. http://dx.doi.org/10.1016/0032-3861(82)90411-6

[6] Kojio, K., Nonaka, Y., Masubuchi, T. and Furukawa, M. (2004) Effect of the Composition Ratio of Copolymerized Poly(Carbonate) Glycol on the Microphase-Separated Structures and Mechanical Properties of Polyurethane Elastomers. Journal of Polymer Science Part B: Polymer Physics, 42, 4448-4458. http://dx.doi.org/10.1002/polb.20303

[7] Kojio, K., Furukawa, M., Nonakaand, Y. and Nakamura, S. (2010) Control of Mechanical Properties of Thermoplastic 
Polyurethane Elastomers by Restriction of Crystallization of Soft Segment. Materials, 3, 5097-5110. http://dx.doi.org/10.3390/ma3125097

[8] Park, J.H., Lee, K.B., Kwon, I.C. and Bae, Y.H. (2001) PDMS-Based Polyurethanes with MPEG Grafts: Mechanical Properties, Bacterial Repellency, and Release Behavior of Rifampicin. Journal of Biomaterials Science, Polymer Edition, 12, 629-645. http://dx.doi.org/10.1163/156856201316883458

[9] Fischer-Cripps, A.C. (2000) Introduction to Contact Mechanics.

[10] Doerner, M.F. and Nix, W.D. (1986) A Method for Interpreting the Data from Depth-Sensing Indentation Instruments. Journal of Materials Research, 1, 601-609. http://dx.doi.org/10.1557/JMR.1986.0601

[11] Van Landingham, M.R. (2003) Review of Instrumented Indentation. Journal of Research of the National Institute of Standards and Technology, 108, 249-265. http://dx.doi.org/10.6028/jres.108.024

[12] Oliver, W.C. and Pharr, G.M. (1992) An Improved Technique for Determining Hardness and Elastic Modulus. Journal of Materials Research, 7, 1564-1583. http://dx.doi.org/10.1557/JMR.1992.1564

[13] Pharr, G.M. (1998) Measurement of Mechanical Properties by Ultra-Lowload Indentation. Materials Science and Engineering A, 253, 151-159. http://dx.doi.org/10.1016/S0921-5093(98)00724-2

[14] Tsui, T.Y. and Pharr, G.M. (1999) Substrate Effects on Nanoindentation Mechanical Property Measurement of Soft Films on Hard Substrates. Journal of Materials Research, 14, 292-301. http://dx.doi.org/10.1557/JMR.1999.0042

\section{Submit or recommend next manuscript to SCIRP and we will provide best service for you:}

Accepting pre-submission inquiries through Email, Facebook, LinkedIn, Twitter, etc.

A wide selection of journals (inclusive of 9 subjects, more than 200 journals)

Providing 24-hour high-quality service

User-friendly online submission system

Fair and swift peer-review system

Efficient typesetting and proofreading procedure

Display of the result of downloads and visits, as well as the number of cited articles

Maximum dissemination of your research work

Submit your manuscript at: http://papersubmission.scirp.org/ 